\title{
THE RELATION BETWEEN PERSONALITY AND LEARNING PREFERENCE
}

\author{
Lilly E. Both \\ Department of Psychology, University of New Brunswick \\ 100 Tucker Park Road, Saint John, NB E2L 4 L5 (Canada)
}

\begin{abstract}
In this study, 106 women ( $M$ age $=23$ years) completed a series of questionnaires online assessing personality traits and facets (subscales), learning preferences (Activist, Reflector, Theorist, Pragmatist), and attitudes toward learning preferences. The results of several hierarchical regression analyses found that a large proportion of variance in learning style was accounted for by personality traits or facets. For example, $43 \%$ of the variance in the Activist Learning Style was accounted for by higher scores on Extraversion, and lower scores on Conscientiousness and Negative Emotionality. When personality facet scores were used as predictors, the proportion of variance jumped to 55\%. Similarly, between $27-31 \%$ of the variance in Reflector, Theorist and Pragmatist Learning Style was accounted for by personality facet scores alone. The results are discussed in terms of attitudes and the need for evidence-based practices.
\end{abstract}

Keywords: Personality, learning styles, attitudes.

\section{Introduction}

The concept of learning styles has been around for some time. Despite a large body of evidence that learning styles are unrelated to educational outcomes (Pashler, McDaniel, Rohrer, \& Bjork, 2008), many people still believe that information is best learned when it is presented in a way that matches their style. In a number of older studies, researchers have found that learning styles (more accurately called learning preferences) can be explained in terms of personality traits. In other words, learning preferences are a subset of personality types (Jackson \& Lawty-Jones, 1996). These older studies, however, focused on Extraversion, Neuroticism and Psychoticism. In recent years, newer and updated measures of personality - measuring all "Big Five" traits and facets - have become available.

\subsection{Purpose of the present study}

The purpose of this study was to replicate and update the literature by examining the relation between all Big Five personality traits and facets (Soto \& John, 2017), learning preference (Activist, Reflector, Theorist, Pragmatist; Honey \& Mumford, 1992), and attitudes toward learning preferences.

\section{Method}

\subsection{Participants}

The sample consisted of 106 women $(M$ age $=23 ; S D=7.6$, range $=19-54$ years $)$ who completed an online survey. The majority of women were university students who were made aware of the study on SONA, an online recruiting platform. However, members of the general public could access the survey online and participate. In terms of education, $14.2 \%$ of the sample had a high school diploma, $70.8 \%$ had some university or community college courses, $14.2 \%$ had a university or community college degree, and . $9 \%$ had some graduate studies training. In terms of marital status, $85 \%$ of the women were single; $12 \%$ were married or common law; and 3\% were divorced. The majority of the sample was Caucasian (92\% White or Caucasian, 3\% Asian, 1\% Black or African Canadian; 4\% Other). As an incentive to complete the survey, participants could choose to be entered into a draw for a $\$ 50$ Amazon gift card. As well, students attending university could earn a bonus point toward their final grade in their course. 


\subsection{Measures}

Demographic Questionnaire. Participants completed a brief demographic measure that assessed age, gender, marital status, education level, and race/ethnicity.

The Big Five Inventory - 2 (BFI-2; Soto \& John, 2017). This inventory assesses personality in terms of five common universal traits or factors. As well, each factor is comprised of three subscale scores known as facets. The scale provides scores for Extraversion (with facets Sociability, Assertiveness, Energy Level), Agreeableness (with facets Compassion, Respectfulness, Trust), Conscientiousness (with facets Organization, Productiveness, Responsibility), Negative Emotionality (with facets Anxiety, Depression, Emotional Volatility), and Open-mindedness (with facets Intellectual Curiosity, Aesthetic Sensitivity, Creative Imagination). In the present study, the measure had excellent internal reliability (Extraversion Cronbach's a $=.86$; Agreeableness $=.78$; Conscientiousness $=.85$; Negative Emotionality $=.90$; Open-mindedness $=.82$ ).

Learning Styles Questionnaire (Honey \& Mumford, 1992). This questionnaire consists of 80 items that assesses preferred learning styles in four domains. The Activist style characterizes someone who likes to jump right into learning activities and enjoys group problem-solving. They are often leaders in discussion groups. The Reflector style is someone who is an introvert who likes to give careful thought to his/her approach. They like to observe and gather evidence before drawing conclusions. Theorists are analytical and logical. They like to test theories and ask the big questions. Finally, Pragmatists like concrete, real world problems with hands-on practical solutions. This measure is commonly used in research. However, in the present study, the internal reliability was questionable (Activist Cronbach's $\mathrm{a}=.75$; Reflector $=.63$; Theorist $=.58$; Pragmatist $=.68$ ).

Attitudes Toward Learning Styles. Participants completed 6 questions (designed for this study) to assess their attitudes toward learning styles. For each item, they rated their response on a scale from $1=$ strongly disagree to $5=$ strongly agree.

\subsection{Procedure}

Participants had access to the survey via their smart phone, tablet or computer, by accessing a link to Qualtrics, an online survey tool. The survey began with a description of the study that included a consent form. Once participants provided consent, the survey began with the demographic measure, and then the remaining measures were presented in random order. The survey took about 30 minutes to complete.

\section{Results}

\subsection{Attitudes toward learning styles}

See Table 1 for responses to these items.

Table 1. Attitudes toward Learning Styles by Response Percentages.

\begin{tabular}{|l|l|l|l|l|l|}
\hline & $\begin{array}{l}\text { Strongly } \\
\text { Disagree }\end{array}$ & Disagree & Neutral & Agree & $\begin{array}{l}\text { Strongly } \\
\text { Agree }\end{array}$ \\
\hline $\begin{array}{l}\text { Students are more likely to achieve academic success when } \\
\text { their learning style matches the instructor's teaching style. }\end{array}$ & 0 & 2.8 & 2.8 & 32.1 & 62.3 \\
\hline $\begin{array}{l}\text { Students learn best when they know what their learning } \\
\text { style is and use strategies to match their style. }\end{array}$ & 0 & 0 & 2.8 & 33.0 & 64.2 \\
\hline $\begin{array}{l}\text { Information is best learned when it is presented in a way } \\
\text { that matches the student's learning style. }\end{array}$ & .9 & 0 & 1.9 & 36.8 & 60.4 \\
\hline $\begin{array}{l}\text { If students use study strategies that match their learning } \\
\text { style, they are more likely to have academic success. }\end{array}$ & .9 & .9 & 1.9 & 33.0 & 63.2 \\
\hline $\begin{array}{l}\text { Learning style matters more than motivation when learning } \\
\text { difficult information. }\end{array}$ & 2.8 & 41.5 & 21.7 & 26.4 & 7.5 \\
\hline $\begin{array}{l}\text { Learning style matters more than effort and persistence } \\
\text { when learning difficult concepts. }\end{array}$ & 6.6 & 50.0 & 16.0 & 18.9 & 8.5 \\
\hline
\end{tabular}

\subsection{Hierarchical regression analyses}

A series of hierarchical regression analyses were conducted predicting each of the four learning styles. In each case, age was added on the first step for control for its effects. On the second step, the 5 personality factor scores were added. Similarly, the regressions were also conducted substituting the personality factor scores with the facets. In all regression analyses, Tolerance and VIF were well within acceptable levels. 
The Activist Learning Style. The overall model was statistically significant and accounted for $43 \%$ of the variance in Activist Learning Styles $(F(6,99)=12.56, p<.001$, multiple $R=.66)$. Age was not a statistically significant predictor, but the personality factors produced a statistically significant change in the model $\left(R^{2}\right.$ change $\left.=.41, F_{\text {inc }}(5,99)=14.30, p<.001\right)$. Significant predictors were Extraversion $(\beta=.52)$, Conscientiousness $(\beta=-.45)$ and Negative Emotionality $(\beta=-.20)$. The adjusted $R^{2}$ value of .40 in the overall model indicates that a large proportion of the variability in the Activist Learning Style was predicted by the personality traits, namely higher scores on Extraversion and lower scores on Conscientiousness and Negative Emotionality.

When facet scores were substituted for the personality factor scores in a separate analysis, the proportion of variance accounted for in Activist Learning Style jumped to 55\% $(F(16,89)=6.68$, $p<.001$, multiple $R=.74)$. Significant predictors were Respectfulness $(\beta=-.28)$ Trust $(\beta=.20)$, and Responsibility $(\beta=-.22)$. The adjusted $R^{2}$ value of .46 in the overall model indicates that a large proportion of the variability in the Activist Learning Style was predicted by lower scores on Respectfulness and Responsibility, and higher scores on Trust.

The Reflector Learning Style. The overall model was statistically significant and accounted for $23 \%$ of the variance in Reflector Learning Styles $(F(6,99)=5.00, p<.001$, multiple $R=.48)$. Age was not a statistically significant predictor, but the personality factors were. Significant predictors were lower Extraversion $(\beta=-.22)$, and higher Conscientiousness $(\beta=.44)$.

When facet scores were substituted for the personality factor scores in a separate analysis, the proportion of variance accounted for in Reflector Learning Style increased to $27 \%(F(16,89)=2.10$, $p=.015$, multiple $R=.52)$. Significant predictors were higher scores on Organization $(\beta=.29)$ and Responsibility $(\beta=.30)$.

The Theorist Learning Style. The overall model was statistically significant and accounted for $24 \%$ of the variance in Theorist Learning Styles $(F(6,99)=5.27, p<.001$, multiple $R=.49)$. Age was not a statistically significant predictor, but the personality factors were. Significant predictors were lower Agreeableness $(\beta=-.41)$, and higher Conscientiousness $(\beta=.63)$.

When facet scores were substituted for the personality factor scores in a separate analysis, the proportion of variance accounted for in Theorist Learning Style increased to $31 \%(F(16,89)=2.45$, $p=.004$, multiple $R=.55)$. Significant predictors were lower Compassion $(\beta=-.31)$, and higher Organization $(\beta=.26)$.

The Pragmatist Learning Style. The overall model was statistically significant and accounted for $13 \%$ of the variance in Pragmatist Learning Styles $(F(6,99)=2.55, p=.025$, multiple $R=.37)$. Significant predictors were Extraversion $(\beta=.23)$ and Agreeableness $(\beta=-.32)$.

When facet scores were substituted for the personality factor scores in a separate analysis, the proportion of variance accounted for in Pragmatist Learning Style jumped to $28 \%(F(16,89)=2.13$, $p=.013$, multiple $R=.53)$. Significant predictors were lower Respectfulness $(\beta=-.40)$ and lower Aesthetic Sensitivity $(\beta=-.34)$.

\section{Discussion}

Over $90 \%$ of women in this study believed that students are more likely to have academic success when teaching and learning strategies match their learning style or preference, despite vast amounts of literature debunking this myth (Pashler et al., 2008). Furthermore, a large amount of variance in learning styles was accounted for by personality scores.

\section{Conclusion}

There is a need for evidence-based practice in the learning styles literature.

\section{References}

Honey, P., \& Mumford, A. (1992). The manual of learning styles. Maidenhead: Peter Honey. Copy of learning styles questionnaire retrieved January, 2019 from www.hrdevelopment.co.nz.

Jackson, C., \& Lawty-Jones, M. (1996). Explaining the overlap between personality and learning style. Personality and Individual Differences, 20(3), 293-300.

Pashler, H., McDaniel, M., Rohrer, D., \& Bjork, R. (2008). Learning Styles: Concepts and evidence. Psychological Science in the Public Interest, 9(3), 105-119.

Soto, C.J., \& John, O.P. (2017). The next Big Five Inventory (BFI-2): Developing and assessing a hierarchical model with 15 facets to enhance bandwidth, fidelity, and predictive power. Journal of Personality and Social Psychology, 113(1), 117-143. 